\title{
DEMOGRAPHIC EXPLORATION OF ACADEMIC SELF-EFFICACY BELIEFS OF SELECTED SENIOR SECONDARY SCHOOL STUDENTS IN OGBOMOSO AREA OF OYO STATE
}

\section{S. T. AKANBI (PhD)}

\begin{abstract}
This study aimed at exploring academic self-efficacy beliefs of Senior Secondary School students using some demographic variables. The study adopted a descriptive survey research design. Two hundred and seventy-nine (279) students randomly selected from selected Senior Secondary Schools in Ogbomoso area of Oyo State participated in the study. The instrument used for the study was the Students' Academic Efficacy Scale with reliability co-efficient of 0.76. Subjecting the data collected to statistical analysis, student t-test was used. Four hypotheses were tested at 0.05 level of significance. The results showed that male students were more self-efficacious than their female counterparts. Also, the students who are older than being in secondary school (especially SS 1 \& SS2), aged 18years and above had lower self-efficacy than students aged 17 years and below. However, significant difference did not occur among the students based on subject combinations and parental educational qualifications. The outcomes of the study were fully discussed and suggestions were made for further studies.
\end{abstract}

Keywords: Self-Efficacy Beliefs, Academic Performance, Parental Academic Qualification, Age, Sex, Subject Combination

\section{Introduction}

The attention of experts in the field of educational psychology has been well drawn into how the performance of students at all levels of academic institutions can be well enhanced. Consequently, various theories have been formulated on what governs the behaviour of individuals (academic performance inclusive). Such theories include those which postulate that people are shaped and shepherded by environmental forces and those which are of the opinion that human behaviour is driven by suppressed inner instincts.

However, current theories in educational psychology have posited that personal cognitions influence instigation, direction, strength and persistence of behaviour (Schunk, cited in Phan and Walker, 2000). One prominent example of personal cognition is self-efficacy which is defined by Bandura (1986) as people's judgments of their capabilities to organize and execute courses of action required to attain designated type of performances. In this socio-cognitive perspective, individuals are viewed as proactive and self regulating rather than as reactive and controlled by biological or environmental forces (Pajare \& Schunk, 2001). According to Pajare and Schunk (2001), this theory is also of the opinion that individuals are understood to possess self-beliefs that enable them to exercise a measure of control over their thoughts, feelings and actions. Bandura (1986) opines that what people think, believe and feel affect how they behave and that the beliefs that the people have about their capabilities are critical elements of their motivation and behaviour.

Consequently, if this theory is applied to the study of children's beliefs about learning specific subjects, one might predict that children with high self-efficacy regarding 
matters would demonstrate greater success (Jinks \& Morgan, 1996). Moreover, Bandura (1986) had already established the fact that students' beliefs about their capabilities to successfully perform academic tasks or their self-efficacy beliefs powerfully influence how they perform in academic endeavors, the higher the sense of efficacy, the greater the effort, persistence and resilience (Pajare\&Schunk, 2001). In the perspective ofPhan and Walker (2000), besides the knowledge and skills one possesses, what individuals believe about themselves and about their academic competence in part helps to govern their academic success in schools. Also, Pajare and Valiente (1999) contended that one's academic attainments can markedly differ from others even when knowledge and skills are of the same level.

Since Bandura propounded his theory of self-efficacy in 1977, experts in the field of educational psychology have applied the construct to solve diverse educational problems in academic settings at various grade levels (primary, secondary, tertiary), content domains (reading, writing, math, computing science) and students ability levels (average, gifted, remedial) (Schunk, cited in Walker 2000). Akanbi (2005a)also suggested that self-efficacy can be applied for the reduction of text anxiety and examination malpractice in public examinations. Additionally, Akanbi (2005b) found positive relationship between academic achievement and self-efficacy of students.

Valiente (2005) explained that self-efficacy does not directly influence the acquisition of knowledge and skills, but does provide a framework for analyzing and explaining what individuals do with the knowledge and skills they possess. Consequently students' self-efficacy beliefs have been identified to influence the scholastic achievement of individuals in relation to making a choice and determining the outcomes one expects (Pajares and Schunk, 2001), goal setting (Schunk\& Swartz, 1993), regulation of competence and subsequent performance (Pajare\& Valiant, 1999), self-concept (Pajare\& Miller, 1994), self-regulation (Schunk, 1996), choice of career or courses (Betz \& Hackett, 1983; Adeyemo, 1998), and attributional feedback (Schunk 1982) to mention just a few. All these factors which may directly influence academic achievement can also be influenced by the level of self-efficacy one possesses.Pajare\&Schunk (2001) simply put the dividends of self efficacy as regards academics this way:

$\therefore \quad$ strong sense of efficacy enhances human eccomplishment and well-being in countless ways. Confident individuals approach difficult tasks as challenges to be mastered rather than as threats to be avoided. They have greater interest and deep engrossment in activities, set for themselves challenging goals and maintain strong commitment to them, and heighten and sustain their efforts in the face of failure. They more quickly recover their confidence after failures or setbacks and attribute failure to insufficient effort or deficient knowledge and skills (p.3-4).

On the contrary, Pajare \& Schunk (2001) observed that people who are pessimistic of their competence may believe that things are tougher than they really are. Such a belief as this, according to Pajare \& Schunk, promotes stress, depression, and narrow vision of how best to solve a problem. It can therefore be concluded, based on this assertion, that self-inefficacy inhibits academic successTo crow it all,Hodges (2005) 
concluded that self-efficacy has been a better predictor of students' academic performance than prior experience which makes it a point of focus to all educational practitioners.

In the view of Valiante (2005), self-efficacy develops through four main sources, namely past experience with the similar task which is in form of interpreted success and failure; verbal and social persuasions in the form of praise, criticism and attribution feedback; vicarious experiences in the form of watching others succeed and fail and physiological indications.

Demographically, the available research findings have shown gender differences in self-efficacy beliefs and have reported that in general, boys tend to be more efficacious than girls (Tiller, 1995;Pajare, 1997; Adeyemo, 2001). However, other researchers have noted that although gender differencesmay occur in academic selfefficacy, it is contingent upon some subject specific domains. For instance, while comparing gender differences in mathematics self-efficacy, Ertmer, Evenbeck, Cennamo, \& Lehman (1994) explained that gifted females' math confidence appeared weakest in math-related college course work and strongest in tasks involving traditionally female activities. Conversely, Luzo (1995) found no significant gender differences in relation to self-efficacy. Also, Tiller (1995) found that the college students' year of study has a significant effect on their level of self-efficacy. According to him, freshmen have a lower level of self-efficacy than sophomores, juniors, and seniors. Hassan, (1984) and Adeyemo, (2001) in their studies found that Science students are more rational than Art students in subject combination. In other words, Science students are more self-efficacious than their Arts counterparts.

The necessity for conducting such a research as this could not be unconnected with the fact that studies on demographic variables that could moderate self-efficacy beliefs of students predominantly focused on gender differences (e.g.Luzo,1995; Tiller, 1995Pajare, 1997; Adeyemo, 2001;) leaving behind other variables that could explain differences in the academic self-efficacy of students. Besides, outcomes of studies on gender differences in relation to academic self-efficacy also vary as could be noted in literature reviewed above. This variation in research outcomes and relative abandonment of other demographic variables give more opportunity to conduct more research on demographic differences in students' academic self-efficacy. Noting that there are other demographic variables that can explain differences in academic selfefficacy of students, the current study focused on parents' educational level, age, subject combination as well as gender

The purpose of the present study in a nutshell was to investigate the self-efficacy beliefs of the senior secondary school students using demographic variables with the main aim of adding to the available research findings in this area.

\section{Hypotheses}

The following hypotheses were tested at the probability level of 0.05 .

1. There is no significant difference between male and female senior secondary school students of Ogbomoso area in their academic self-efficacy beliefs. 
2. There is no significant difference between old and young senior secondary school students of Ogbomoso area in their academic self-efficacy beliefs.

3. There is no significant difference between the students of Ogbomoso area from lower parental educational qualification and their counterparts from higher parental educational qualificationin their academic self-efficacy beliefs.

4. There is no significant difference between science students of Ogbomoso area and their counterparts in Arts and Commercein their academic self-efficacy beliefs.

\section{Methodology}

\section{Research Design}

The design used was descriptive survey. This design was employed to allow the researcher collect information from a large number of participants. It also gives room for making generalization from the outcomes of the study without necessarily manipulating any variables.

\section{Population, Sampling and Sampling Technique}

The target population for this study include all senior secondary school students in Ogbomoso township. There are sixty-two senior secondary schools in the area of the study with population of nineteen thousand, one hundred and eighteen $(19,118)$ students, comprising 9,556 male and 9,562 females studentsas at the time of the study. However, theparticipants for the study comprised two hundred and seventy-nine (279) senior secondary school students randomly selected from four (4) selected senior secondary schools in Ogbomoso area of Oyo State. The schools are: Maryland Catholic Grammar School, Royal International College, The Apostolic Grammar school and Baptist Secondary Grammar School, Ahoyaya, representing both public and private schools. A further breakdown of the analysis of participants' demographic information is as shown in Table I below.

Table 1: Distribution of Participants' Bio-Data

\begin{tabular}{|llll|}
\hline & Category & No & $\%$ \\
Age & Male & 133 & 47.7 \\
& Female & 146 & 52.3 \\
& $12-14$ years & 34 & 12.2 \\
& $15-17$ years & 141 & 50.5 \\
Parent's Educational & OND \& below & 161 & 32.6 \\
Qualification & 18-20 years & 91 & 4.7 \\
Subject Group & Higher than OND & 118 & 57.7 \\
& Art & 66 & 42.3 \\
& Commercial & 76 & 23.7 \\
& Science & 137 & 27.2 \\
\hline
\end{tabular}




\section{Instrument}

The instrument used for the collection of data was a self-constructed scale called "Students' Academic Efficacy Scale". The scale was divided into two sections; Section A which contains the Personal Data Information and Section B which consists of 25 itemsdesigned to measure the students' Academic Self-Efficacy. The scale utiliżes a four point scale format with response ranging, from (1) really agree, (2) agree, (3) disagree, and (4) really disagree; The higher the score, the higher the academic self-efficacy of the student because the items were negatively worded.

\section{Validity and Reliability of the Research Instrument}

To ascertain the validity of the research instrument, the face validity and content validity were done by a team of experts in the field of educational psychology and test and measurement.All the corrections suggested by these experts were effected before the test administration. For the internal consistency reliability of the test, the Cronbach's alpha coefficient was used and it was 0.76 . Also a test-retest of the scale within a period of two weeks read 0.83 which suggests that the reliability of the instrument is high.

\section{Procedure}

The questionnaire was administered to the students through the help of some school teachers and counsellors. The distribution and retrieval of the questionnaire to the participants in their respective schools lasted a span of two weeks. Out of three hundred copies of the questionnaire distributed, two hundred and eighty three (283) were returned from which 4 were not properly filled. Consequently, the 279 copies of questionnaire properly filled were used for analysis in this study.

\section{Method of Data Analysis}

The data collected were analyzed using t-test statistics.

\section{Results}

To test the first null hypothesis, which stated that there is no significant difference between male and female senior secondary school students in their academic selfefficacy belief, the mean scores of male and female students were subjected to statistical analysis using the student t-test. The result is as shown in Table II.

Table II: T-test Comparison of Male and Female Students' Self-efficacy Belief.

\begin{tabular}{llllllll}
\hline Variable & $\mathrm{N}$ & $\mathrm{X}$ & S.D. & Df & t-cal. & t-crit. & Remark \\
Male & 133 & 76.5 & 10.20 & 277 & 3.35 & 1.96 & Significant \\
Female & 146 & 70.59 & 11.86 & & & & \\
\hline
\end{tabular}

Going by the result on Table II, it is obvious that the t-calculated (3.35) is greater than the t-critical (1.96). Male students have a mean score (76.50) which is higher than their female counterparts (70.59). The null hypothesis is therefore rejected. This means, statistically, significant difference existed in the academic self-efficacy of 
students based on gender differences. Male students were more self-efficacious academically than female students.

In the second hypothesis, it was stated that age would not constitute a significant difference in the academic self-efficacy beliefs of senior secondary school students. To test this hypothesis, the mean scores of the participants were compared using t-test statistics. The result is as presented in Table III.

Table III: T-test showing the Comparison of Old and Young Students' Academic Self-efficacy Belief.

\begin{tabular}{llllllll}
\hline Variable & $\mathrm{N}$ & $\mathrm{X}$ & $\mathrm{S} . \mathrm{D}$. & $\mathrm{df}$ & $\mathrm{t}$-cal. & t-crit. & Remarks \\
\hline Young(between12-17) & 175 & 75.34 & 11.46 & & & & \\
Old (18 years and above) & 104 & 69.70 & 10.62 & 277 & 3.03 & 1.96 & Significant \\
\hline
\end{tabular}

Based on the result on Table III, the t-calculated (3.03) is also greater than the tcritical (1.96). The outcome of this result negates the stated hypothesis. The younger students (age 12-17years), score higher ( $X=75.34$ ) than their older counterparts (age 18years and above) with mean score of 69.7. The null-hypothesis is therefore also rejected. This result suggests that the difference in the academic self-efficacy belief of students based on age differences is significant with the younger students being more academically self-efficacious than older students.

The result of the third hypothesis which stated "There is no significant difference between the academic self-efficacy beliefs of the senior secondary school students based on their parents' academic qualification" is also presented in Table IV.

Table IV: T-test Comparison of Students' Academic Self-efficacy Beliefs based on Parents'Academic Qualification.

\begin{tabular}{llllllll}
\hline Variable & N & X & S.D. & Df & t-cal. & t-crit. & Remarks \\
\hline $\begin{array}{l}\text { Low parental educational } \\
\text { qualification (OND and below) }\end{array}$ & 161 & 72.7 & 11.58 & & & & \\
$\begin{array}{l}\text { High Parental educational } \\
\begin{array}{l}\text { qualification (First degree and } \\
\text { above) }\end{array}\end{array}$ & 118 & 74.4 & 11.42 & & & & Significant \\
\hline
\end{tabular}

As could be seen from the Table IV, the t-observed is not significant at 0.05 probability level (t-observe $=0.904$, $t$-critical $=196 ; \mathrm{P}>0.05$ ). In the light of this result, the third hypothesis is upheld. This indicates that difference in the self-efficacy belief of secondary school students is not stutistically significant based on parents' academic qualification.

The fourth hypothesis which postulates that there is no significant difference between the senior secondary school students based on their subject combinations is also subjected to t-test analysis. The result is as shown in Table IV.

Table V: T-test Comparison of Senior Secondary School Students' Academic Self-efficacy based on their Subject Combination.

\begin{tabular}{llllllll}
\hline Variable & N & X & S.D. & df & t-cal & t-crit & Remarks \\
\hline Art and Commercial & 143 & 72.05 & 11.94 & 277 & 0.889 & 1.96 & Not Significant \\
Science & 137 & 73.65 & 11.02 & & & & \\
\hline
\end{tabular}


The above hypothesis was accepted as there was no significant difference in the selfefficacy beliefs of the senior secondary school students based on their subject combinations. The t-critical (1.96) is greater than t-calculated (0.889). The hypothesis is therefore confirmed. It could therefore be inferred from this finding that no significant difference exists in the self-efficacy belief of students on the account of subject combination.

\section{Discussion}

Male students were more self-efficacious than female students. This finding corroborates the finding of Tiller (1995), Pajare, (1997 and 1999), and Pajare\& Miller (1994 and 2001) who found that boys tend to be more self-efficacious than girls. The probable reason for the outcome of this study could be the fact that in cultural setting like Nigeria, much importance is placed on male gender. Males are made to feel superior to females; hence much importance is placed on their education than that of females. The result is also in line with the assertion of Adeyemo (2001) was noted that male children are motivated, urged and even compelled to excel than their female counterparts. Consequently, this might have a negative implication on the selfefficacy beliefs of female students, hence the difference observed in the academic self-efficacy of students in relation to gender disparity.

The outcome of the second hypothesis also revealed that students with age 17years and below are more self-efficacious than those aged above 18years. This should not constitute a spark of surprise as the students above 18 years of age are, under normal circumstance, older than being in SS1 or SS2. Their age mates oftentimes have already passed out of secondary school. Several factors might be responsible for these students beingin secondary school at that age, one of which might be repeated failure. Such negative past experience might be perceived by the students as barrier to their future accomplishment. This has been explained by Brown (1999), that poor grades and other negative assessment of ability lower self-efficacy beliefs.

The parental educational level did not affect the self-efficacy beliefs of the students in line with the outcome of this study. Actually, one might have expected that students who came from parents with higher educational background to be more selfefficacious than those participants with parents with lower level of education because of the expected motivation, encouragement and most importantly the modeling roles their parents might serve to them. It must however be noted that, although, the students with parents with lower level of education might not be able to enjoy the above ingredients of self-efficacy directly from their parents, they equally have siblings, uncles or other relatives, who could equally assist developingtheir selfbeliefs. Also, teachers, counsellors and other important personalities might serve as models which students from lower educational background might wish to emulate in academia. Besides, none of the students used for this study indicated that their parents were complete illiterate. The least educational qualification indicated was Senior School Certificate. This indicates that every participant has parents who know the value of education and can serve as sources of encouragement to him or her.

The fourth hypothesis which postulated that significant difference does not exist among senior secondary school students based on their subject combinations was also upheld. The possible explanation of this result could be the fact that the availability 
of guidance and counseling services in schools which often give career counseling/talk might have helped both the science students and others in their proper placement, and the students' acceptance of where they are placed knowing the fact that there is no subject combination without its future prospects. However, the outcome of this study seems to negate the works of Hassan (1984) and Adeyemo (2001) who found that science students are more rational than arts students in subject combination. But, looking at the mean scores of the students, the science student (73.65) scored higher than students from art and commercial classes (72.05). This is to show that the finding has not totally deviated from that of Hassan and Adeyemo but stresses that although science students are more self-efficacious than the arts and commercial students; the difference is not statistically significant.

\section{Recommendations and Conclusion}

Based on the finding that females are low self-efficacious than males, the educational/counselling psychologists should develop a therapeutic package which will focus on enhancing the self-efficacy of females. Society should also be made to know the fact that both males and females are of equal importance; hence females also should be motivated towards enhancing their academic performance.

Also, based on the findings of this study, it is obvious that when students find themselves in a class that does not fit their status as a result of age (which may be a consequence of negative past experience through repeated failure) they tend to experience low self-efficacy beliefs, and as a result, under achieve academically. The study consequently recommends that educational psychologists and the policy makers should look into what can be done for students who are repeating classes continuously and do not have age to their favour. The full implementation of the 6-33-4 system of education is highly recommended where students found not being capable of coping with the academic rigors of senior secondary schools will be sent for technical education before they are adversely affected by their under-achievement.

It is encouraging to find that no significant differences exist between the students based on their parents' academic qualifications and the students' subject combinations. This could be the positive effect of counselling services in schools.It is therefore recommended that both the school counsellors and teachers should work hand in hand towards enhancing the self-efficacy of the students, as this will in turn enhance their academic achievement.

\section{References}

Adeyemo, D. A. (1998).Effect of didactic mode of career education and values clarification on the career decision-making self-efficacy of secondary school students.Nigerian Journal of Applied Psychology,4(1): 1-15.

Adeyemo. D. A. (2001).Self-efficacy and subject enrolment in secondary schools: Anempirical inquiry. Ibadan Journal of Educational Studies, 1 (1):86-95.

Akanbi, S. T. (2005a,April): Self-efficacy strategies as therapeutic devices for reducing test anxiety and examination malpractice in public examinations. Paper presented at the

WAEC Monthly Seminar. 
Akanbi, S.T. (2005b). Self-efficacy as a correlate of academic performance among secondaryschool students in Ogbomoso area of Oyo State, Nigeria.Nigerian Journal of Applied Psychology,9: 243-256.

Bandura, A. (1986).Social foundations of thought and action: A social cognitive theory. Englewood Cliffs, NJ: Prentice Hall.

“Betz, N. E. \& Hackett, G. (1983).Relationship of mathematics self-efficacy expectations to the selection on science-based majors.Journal of Vocational Behaviour, 23: 239-345.

Brown, B. L. (1999): Self-efficacy beliefs and career development.Eric Digest, No. 205. Retrieved April 25,2005 fromhttp://ww' Ericfacility.Net/ericdigest/ed429187.html.

Ertmer, P. A., Evenbeck, E., Cennamo, K.S., \& Lehman, J.D. (1994).Enhancing selfefficacy for computer technologies through the use of positive classroom experiences.Educational Technology Research and Development: 42: 45-62.

Hassan T. (1984).Identification and classification of students with rational and irrational subjects'combination. Psychology for Everyday Living, 3 (1):5-12.

Hodges C. B. (2005).Development of a scale measure self-efficacy for learning mathematics asynchronously. Tenth Annual Instructional Technology Conference, Middle Tennessee State University.April 3-5.

Jinks, J. \&Morgan V.L. (1996).Students' sense of academic efficacy and achievement inscience: A useful new direction for research regarding scientific literacy?Retrieved 2005.http://unr.edu/homepage/jcannon/ejse/jinksmor.html/top.

April25,

Luzo, D. A. (1995).The relative contributions of self-efficacy and locus of control to theprediction of career maturity.Journal of College Student Development, 36:6166.

Pajares, F. (1997).Current directions in self-efficacy research, In M. Maehr\& P. R.Pintrich (eds.). Advances in Motivation and Achievement, 10: 149. Greenwich,CT: JAY Press.

Pajares, F., \&Miller. M. D. (1994). The role of self-efficacy and self-concept beliefs in mathematical problem-solving: A path analysis. Journal of Educational Psychology,86: 193-2003.

Pajares, F., \&Schunk, D. H. (2001).Self-beliefs and school success: self-efficacy, selfconcept, and achievement. In R. Reiding\& S. Rayner(eds.) Perception ( $p p$. 239-266).London: Ablex Publishing.

Pajares, F. \&Valiente, G. (1999): Grade level and gender differences in the writing of self-beliefs of middle school students. Contemporary Educational Psychology,24: 390-405.

Phan, H. \& Walker, R. (2000).Prediction and mediational role of mathematics selfefficacy: A path analysis. Retrieve February 15, 2005 from http//w'ww.aare.edu.au/oopap/phaoo22/htm.

Schunk, D. H. (1982).Effects of effort attributional feedback on children's perceived self-efficacyand achievement. Journal of Educational Psychology.74:548-556.

Schunk, D. H. (1996).Goal and self-evaluate influence during children's cognitive skillleaming.American Educational Research Journal,33:359-382.

Schunk, D. H., \& Swartz C. W. (1993).Goals and progress feedback effects on selfefficacy and writing achievement. Contemporary Educational Psychology' 18:337354. 
Tiller, D. (1995).Self-efficacy in college students. Retrieved February15, 2005 fromhttp://www.mwsc.edu/psvchologwesearch/psv302/fa/95tiller.htm

Valiente, G. (2005).Can Professors influence the writing confidence of college students? : The power of feedback on the writing self-efficacy beliefs of college students

Retrieved

February15,

2005

fromhttp://www.rollins.edu/effectiveteaching/scholarteachlinks-examples-

valiante.doc + self + efficacv + and $+n 8$. 